\title{
THE TRANSITION FROM ARCHAEOCETES TO MYSTICETES: LATE OLIGOCENE TOOTHED MYSTICETES FROM NEAR CHARLESTON, SOUTH CAROLINA
}

\author{
BARNES*, Lawrence G., Section of Vertebrate Paleontology, Natural History Museum of Los \\ Angeles County, 900 Exposition Boulevard, Los Angeles, California, 90007, U.S.A.; SANDERS, Albert \\ E., The Charleston Museum, 360 Meeting Street, Charleston, South Carolina, 29403, USA.
}

A previously undescribed new family of archaic fossil toothed mysticetes includes new three species in two new genera of cetaceans from Late Oligocene deposits near Charleston, South Carolina. These medium- to large-sized whales have large, basilosaurid-like cheek teeth with closely positioned and apically-directed denticles on their anterior and posterior margins. They differ from basilosaurids by having retained an $\mathbf{M}^{3}$ and having an extra posterior lower molar $\left(\mathrm{M}_{4}\right)$, both of which are absent in basilosaurids. They also share many cranial characters with baleen-bearing mysticetes, including a laterally-directed antorbital process of the maxilla, a temporal crest along the posterior border of the flat and nearly horizontal supraorbital process of the frontal, short zygomatic arches, enlarged peribullary sinuses, and a loose mandibular symphysis.

The most primitive new genus in the family, represented by a new species from the Chandler Bridge Formation, is a large animal with a skull nearly two meters long and with an elongate, tubular rostrum, a slender and thin supraorbital process of the frontal bearing a sharp temporal crest on its posterior border, a corrugated and grooved palate, short and up-turned nasal bones surrounding a central exposure of frontals, upper cheek teeth with intervening spaces as in basilosaurids, and a corrugated mandibular articular surface but a loose mandibular articulation.

The other new genus in the family includes two smaller and more highly evolved species which have a short, abruptly tapered rostrum that is wider at its base, crowded and imbricated upper molars $\left(\mathrm{M}^{1 \cdot 3}\right)$, and a smooth mandibular articular surface with a loose mandibular articulation. The smaller and geologically older of the two species in this genus is from the Ashley Formation, and has a lightly built rostrum, large teeth, slender zygomatic process of the squamosal, smooth palate, small occipital condyles, smooth occipital shield, and a large periotic. The larger and geologically younger of the two species in the genus, from the overlying Chandler Bridge Formation, differs from the earlier species by having a heavier and thicker rostrum, smaller teeth, correspondingly smaller embrasure pits on both the palate and mandible, a very inflated zygomatic process of the squamosal, a more corrugated palate, a very thick lateral wall of the braincase, a more massive supraorbital process of the frontal, larger occipital condyles, a more rugose occipital shield, and a smaller periotic.

These fossils are the first reported toothed mysticetes from the Atlantic realm. The new family is more primitive than the small-toothed aetiocetid mysticetes from the North Pacific, and differs from the Llanocetidae of the South Pacific, which have large, widely spaced cheek teeth with separated and divergently-splayed denticles on the anterior and posterior margins. Discovery of this group proves unequivocally that the suborder Mysticeti (baleen whales) evolved from the subfamily Dorudontinae of the archaeocete family Basilosauridae, and adds to evidence for the monophyly of all Cetacea. 